Published in "International journal of contemporary hospitality management", 2019, vol. 31, no. 4, pp. 1995-2013, which should be cited to refer to this work.

DOI : $10.1108 /$ IJCHM-02-2018-0145

\title{
Effects of Host Incentives on Multiple Listings in Accommodation Sharing
}

\author{
Structured Abstract
}

\section{Purpose:}

Despite the importance of hosts who contribute to the success of accommodation sharing through sharing underutilized space with guests, current literature sheds little light on what exactly incentivizes hosts to grow their properties. This study investigates the effects of multifaceted motivations including financial benefits, online social interaction, and membership seniority, and their interplay on hosts' multiple listing behavior.

\section{Design/methodology/approach:}

The study is instantiated on real-world business data collected from an accommodation-sharing platform in China. The dataset includes 3,199 observations of 252 multi-listing hosts in Beijing who managed 815 properties from September 2012 to October 2016.

\section{Findings:}

The study discloses that financial benefits, online social interaction, and membership seniority significantly incentivize hosts to list multiple properties on the accommodation-sharing platform. In particular, the social incentive is the most important driver among the three. With a 1\% increase in online social interactions, the number of properties operated by a host would increase by $13.5 \%$. While the financial benefits and online social interaction motivate hosts to engage in the multi-listing behavior, such effects are significantly mitigated as the membership seniority increases.

\section{Research limitations/implications:}

This study adds to the extant literature a unique yet less researched perspective of supply expansion driven by hosts. It also provides important practical implications for managing multiple properties for a healthy and viable accommodation-sharing community.

\section{Originality/value:}

While a majority of the extant research on the sharing economy primarily takes a consumerrelated perspective, this study addresses a different and original topic about hosts' multiplelisting behavior that drives the supply of accommodation sharing. It is a first empirical investigation of the increase of accommodation sharing supply with host motivations explained.

Keywords: accommodation-sharing; sharing economy; multiple listing; host incentives; data analytics 


\section{INTRODUCTION}

The growth of the sharing economy, particularly accommodation-sharing services, has drawn considerable attention from both the industry and academia (Botsman and Rogers, 2011; Heo, 2016). A PricewaterhouseCoopers study estimated that accommodation-sharing services are among the most prominent sharing economy sectors in Europe, generating nearly $€ 4$ billion in revenues and facilitated $€ 28$ billion of transactions in 2015 (Vaughan and Daverio, 2016). Accommodation-sharing services have also flourished in developing countries such as China, exemplified by Chinese variants of Airbnb such as Xiaozhu.com and Tujia.com. The success of accommodation-sharing businesses is attributed to many macro factors, including the sluggish world economy in the late 2000s (Parker et al., 2016), a widespread adoption of social networks and mobile technologies (Guttentag, 2015), and the increased awareness of community and trust among consumers (Botsman and Rogers, 2011).

Compared to the hotel industry that builds its supply on huge investment and integrations, accommodation-sharing services rely on numerous grassroots hosts with a vast geographical reach (Parker et al., 2016). As of January 2018, Airbnb amassed 640,000 hosts, of which 200,000 were senior hosts aged over 60 that are among the fastest growing host demographic (Airbnb, 2018). It is not only the sheer number of hosts but also the type of hosts that matter to the growth of sharing accommodation, which is primarily driven by the willingness of individual hosts to list their properties on the platform. A handful of studies have discussed the importance of multilisting hosts - who operate multiple properties to capitalize on short-term rentals - in driving the growth of Airbnb (Breese, 2018; Kwok and Xie, 2018; Xie and Mao, 2017). Because of the massive number of multi-listing hosts, the growth of accommodation-sharing services seems to undergo an exponential growth that traditional hotels are not able to match. Such a striking 
difference of supply between the two began to surface as Brian Chesky, co-founder of Airbnb, tweeted in early 2014: "Marriott wants to add 30,000 rooms this year. We will add that in the next two weeks."

Despite anecdotal discussions on hosts' multiple listing behavior on the platform (Breese, 2018), empirical research has yet to examine what affects such behavior (e.g., Kwok and Xie, 2018; Xie and Mao, 2017). Several puzzles are still unsolved regarding the phenomena of multilisting that require empirical work. For example, what drives hosts to multi-list properties on the platform? Is their behavior driven by financial returns and/or by other non-monetary benefits (e.g., social and experiential)? Part of the reason for the unsolved puzzles is a lack of data on the actual behavior or activities of hosts. The literature will benefit from research that can collect behavioral evidence of hosts for an empirical investigation of how multifaceted incentives would affect hosts' multiple listing behavior.

We add to the literature by investigating the effects of financial, social, and experiential incentives that motivate hosts to multi-list their properties on an accommodation-sharing platform. Specifically, our research question is twofold: (1) whether financial benefits, online social interactions, and membership seniority would affect hosts' multiple listing behavior; (2) how would these incentives interplay with each other to determine hosts' multiple listing behavior? We adopted a data analytics approach to collecting, analyzing, and interpreting online observational evidence of host multiple listing behavior for business insights. Our findings shed light on the drivers of the supply of accommodation sharing through the lens of host listing expansion, an area that is currently untapped in previous research. The study also generates a better understanding of the hosts' multiple listing behavior that can benefit business practice and policymaking in managing the accommodation-sharing hosts. 


\section{LITERATURE REVIEW}

Economic analysis of host behavior on the supply side of the sharing economy and guest behavior on the demand side is grounded on the two-sided market model (Parker and Van Alstyne, 2005; Rochet and Tirole, 2008). This model underscores a platform that connects two or multiple sides of mutually dependent users (e.g., hosts versus guests on sharing accommodation platforms), suggesting that interactions between hosts and guests are at the heart of host behavior. In what follows, we first lay out the two-sided market model and then discuss three incentives (financial, social and experience) that drive hosts' multiple listing behavior as well as the interplay of the three incentives. We conclude this section by proposing a research framework that delineates the research hypotheses.

\subsection{Accommodation Sharing in the Two-sided Markets}

The two-sided model is credited for its ability to leverage various network effects on the platform, thereby increasing producer surplus and social welfare (Parker and Van Alstyne, 2005). It has been used to explain firm pricing and expansion behavior in different contexts, ranging from media, credit cards to various information products and software packages, all of which entail a platform to connect two types of interdependent users (Gomes, 2014; Parker and Van Alstyne, 2005). Nevertheless, very few references in the literature have drawn to this model in explaining the growth of accommodation sharing and hosts' multiple listing behavior (Evans and Schmalensee, 2016). This is probably because tourism and hospitality researchers tend to emphasize the sharing and alternative use of extra resources instead of the workings of the platform. In the two-sided market model, the proliferation of accommodation sharing is due to various network effects that are scaled up by the Internet and mobile technologies (Evans and 
Schmalensee, 2016). When it comes to explaining host behavior, the network effects indicate that the number of hosts on the platform can affect the growth of the accommodation-sharing services, which in turn can be affected by the number of guests. The more the guests, the more the hosts are willing to list their properties on the platform, suggesting a positive cross-side network effect from guests to hosts.

\subsection{Financial Gains and Growth of Multiple Properties}

Given the enormously high value and scarcity of houses, the sharing economy is featured by sharing accommodation, which gradually becomes an alternative for people not only to avoid the depreciation of their housing assets in economic downturns but also to generate economic benefits. Jefferson-Jones (2015) argued that short-term rentals on Airbnb could help split the economic burdens of home ownership between owners and users on a temporary basis. Moreover, the presence of Airbnb properties can increase the value of spare properties by escalating the price in the housing market. Litvak (2016) compared two cities in Florida and found that the city of Anna Maria, which allowed Airbnb to operate, recorded a nearly twofold increase in home prices compared to the city of Holmes Beach, which banned Airbnb. Because the financial gains can be scaled up on these platforms, hosts have the motivation to list more properties so long as the financial benefits outweigh the benefits from the use of the same resources in the real estate markets (Litvak, 2016). It thus becomes clear that the financial benefits that hosts can reap are the primary incentive for hosts to list multiple properties on accommodation-sharing platforms.

Despite the fact that hosts list their houses or apartments as an economic expediency for avoiding losses and maintaining the value of their properties in economic hardships (Botsman and Rogers, 2011), studies have shown that they tend to monetarize and capitalize the so-called 
hospitality network in the long run in order to enhance social interactions with guests (Ikkala and Lampinen, 2015; Lampinen and Cheshire 2016). Both multiple properties and professional hosts resemble some entrepreneurial activities, in which hosts evolve as micro-entrepreneurs whose objectives are not to maintain the value of spare resources but to maximize the financial gains of the hospitality network. Recent studies have shown that multiple properties have been proliferating on Airbnb and contributing to platform revenues (Slee, 2016). The entrepreneurial aspirations would boost hosts' multiple listing behavior in the long run. We thus propose:

H1: Financial gains are positively associated with hosts' multiple listing behavior on accommodation-sharing platforms.

\subsection{Online Social Interactions and Growth of Multiple Properties}

Among the most credited attributes of the sharing economy is a trusted marketplace created on accommodation sharing platforms, which is not only a reason but also an outcome of social interactions (Kakar et al., 2016; Jefferson-Jones, 2016). For instance, Airbnb aims to enhance consumer experience and social interactions as well as to foster trust between hosts and guests (Lampinen and Cheshire, 2016). Some researchers argued that the host-guest interaction, rather than the property, is the primary asset shared by hosts and guests as well as a primary source of customer satisfaction (Jung et al., 2016). Lampinen and Cheshire's (2016) study found that social interactions with guests, opportunities to meet different guests, and gratification of being a good host are the intrinsic motivations of hosts to engage in accommodation sharing, which are beyond the financial benefits they recouped. Rather than being displaced by financial benefits, social interactions are strengthened by financial benefits (Lampinen and Cheshire, 2016).

While social interactions between hosts and guests through physical contact offline are different from reciprocal online reviews, online reviews are reputation assets that hosts can 
accumulate through interaction with guests either offline or online. The reciprocity of online reviews is established when hosts and guests can rate the trustworthiness of each other by disclosing a broad array of information before, during, and after a transaction. Zervas et al. (2015) found that Airbnb allows reciprocal reviews and thus garners proportionally higher ratings (4.5 stars and above) than TripAdvisor, which only allows customers to rate businesses unilaterally. Fradkin et al.'s (2016) study corroborated these results and attributed the higher ratings on Airbnb to the reciprocal nature of customer reviews.

On accommodation sharing platforms, hosts have the incentive to engage in the sharing community and want to collect feedback to improve service quality through responding to customer reviews. According to Fradkin et al. (2016), accommodation sharing platforms can encourage more social trips through reciprocity in online reviews, which in turn lowered the reporting of negative experiences, if any. This result implies that it is online social interactions that reduce negative reviews and therefore incentivize hosts to participate in social communications with their potential guests actively. Lee et al. (2015) found that hosts' prompt response to guest inquiries is positively associated with room sales on Airbnb. We, therefore, argue that these social benefits would not only affect guests in meeting their needs but also motivate hosts to engage in accommodation-sharing services. Hosts craving more social benefits would be more likely to list multiple properties. We, therefore, propose:

H2: Online social interactions are positively associated with hosts' multiple listing behavior.

\subsection{Membership Seniority and Growth of Multiple Properties}

Managing properties on accommodation-sharing platforms requires sufficient experience and expertise of hosts. It was also found that membership seniority, measured by how long hosts 
have operated on an accommodation-sharing platform, affects host behavior and performance (Lee et al., 2015; $\mathrm{Wu}, 2016$ ). Hosts who use the platform longer can accumulate more information of not only their transactions and properties but also guests, and can, therefore, better serve their guests ( $\mathrm{Wu}, 2016)$. This result suggests a learning curve on the host side to increase operation performance, indicating that hosts' knowledge can be progressively updated through trading with guests on the platform as his or her membership lengthens (Wu, 2016). This means that the more senior a host is regarding the length of membership, the more information and knowledge he or she can possess, and the more confident he or she would be in operating multiple properties.

Because sharing economy markets are characterized by information uncertainty, acquiring market information through extended membership is crucial for hosts to maintain healthy and viable accommodation-sharing services. According to $\mathrm{Wu}$ (2016), a novice host is normally uncertain about his or her property-specific quality or about how much guests would value his or her property, and therefore finds it difficult to charge an appropriate price. Lee et al.'s (2015) study showed that membership seniority was among the most significant factors positively associated with room sales on Airbnb. Because senior membership boosts confidence among potential guests, brings expertise and generates financial returns for hosts, hosts are more likely to multi-list properties. Therefore, we hypothesize:

H3: Membership seniority is positively associated with hosts' multiple listing behavior.

\subsection{The Interplay of Host Incentives in Multiple Properties}

A couple of studies have shed light on the interdependence of different types of incentives in affecting host behavior, especially regarding social benefits and interactions that can be intensified by financial benefits on the platform (Ikkala and Lampinen, 2015; Lampinen 
and Cheshire, 2016). This leads us to explore the complexity of host behavior by referring to three interdependent needs, namely achievement, affiliation, and need for power, proposed by McClelland (1961). Specifically, the need for achievements such as financial gains from operating accommodation-sharing services increases hosts' economic capability of winnowing guest candidates to the most desired ones (Ikkala, 2014). The affiliation need is for open and sociable interpersonal relationships, and a desire for cooperation and mutual understanding, which can be established through actively communicating and interacting with customers on the platform (Jefferson-Jones, 2016). The need for power in the virtual community can be met by extending membership seniority or gaining experience (Xie and So, 2018). These three needs constitute an integrated framework, in which they complement each other in motivating an individual to take actions and achieve his or her behavioral goals (McClelland, 1961). Lampinen and Cheshire's (2016) study particularly showed that the presence of financial benefits does not crowd out social benefits and interactions but rather strengthens these benefits.

Through socially interacting with guests online, hosts signal their genuine care to guests (Xie et al., 2014). When a service failure is reported in a customer comment, hosts can remedy the failure through their active responses (Lee and Song, 2010); when a positive review is posted, hosts can acknowledge the customer satisfaction by responding with appreciation. Compared to those who do not enjoy such connection with guests, a host committed to maintaining online social interaction is more likely to make financial gains from accommodation sharing and, consequently, is more likely to engage in the multiple listing behavior. That is, increased online social interactions would positively moderate the relationship between financial benefits and the multiple listing behavior of hosts. Similarly, in the presence of financial benefits, hosts can confidently signal their success of gaining transactions from previous guests, 
because financial achievement can serve as a signal of host quality in meeting customer needs and securing transactions with them. Thus, financial benefits lay a solid foundation for hosts to confidently interact with guests (Ikkala and Lampinen, 2015) and convincingly promote their properties. Therefore, increased financial benefits would positively moderate the relationship between online social interactions and the multiple listing behavior of hosts. Combining two moderation effects, we argue that financial benefits and online social interactions are interdependent, jointly motivating hosts to list more properties. We hypothesize:

H4a: Financial incentive and social incentive complement each other in affecting the multiple listing behavior of hosts.

Ample evidence suggests that host participation in accommodation sharing is driven by financial benefits, which in turn facilitate social interactions and thereby enhance the hosting experience (Ikkala, 2014; Ikkala and Lampinen, 2015). Previous studies have shown that accommodation-sharing services can generate more financial benefits to hosts than the use of their properties in real estate and hotel markets (Jefferson-Jones, 2015; Litvak, 2016). Therefore, not only do financial benefits motivate hosts to participate in accommodation sharing but also encourage the multiple listing behavior of hosts. On the other hand, incentives in relation to the experience of hosts can help hosts better recoup the financial profits through active learning ( $\mathrm{Li}$ et al., 2015; Wu, 2016). Hosts with more experience on the platform can stimulate a learning effect, which not only reduces information friction on the platform but also equips them with experience to better utilize the platform ( $\mathrm{Wu}, 2016)$. Having such experience can help hosts acquire the knowledge of the platform, ending up with financial benefits in subsequent transactions. We, therefore, hypothesize:

H4b: Financial incentive and experience incentive complement each other in affecting the 
multiple listing behavior of hosts.

It is clear that social incentives are tethered to experience incentives, particularly membership seniority on accommodation sharing platforms ( $\mathrm{Wu}, 2016)$. While the experience of hosts operating on a platform may not necessarily indicate the density of social interactions, experience incentives are positively associated with the opportunities for stimulating host-guest interactions in the long run. Other variants of accommodations-sharing services, such as Couchsurfing, regard social incentives as the principal reason for hosts to operate on the platform (Jung et al., 2016). On these platforms, social incentives displace financial ones as the only objective that hosts, or social entrepreneurs, would pursue (Martin et al., 2015). Since the sharing economy in general still maintains the essence of sharing built on social incentives, hosts with senior membership value social incentives as one of their entrepreneurial achievements. In this sense, McClelland's (1961) study lays out a theoretical foundation for us to explore the need of affiliation in host behavior that aims at establishing social community and interactions. We, therefore, hypothesize:

H4c: Social incentive and experience incentive complement each other in affecting the multiple listing behavior of hosts.

\subsection{Research Framework}

Figure 1 presents a research framework, which depicts the three incentives as well as their relationships with the multiple listing behavior of hosts. We investigate how financial, social, and experience incentives and their interplay affect the multiple listing behavior of hosts. In addition, we control a group of host demographic and behavioral characteristics that may affect their multiple listing behavior. It is worth noting that an overwhelming majority of studies on sharing accommodation were devoted to the Western context, in which the 2007/08 financial 
crisis was cited as one of the fundamental factors (Botsman and Rogers, 2011). It becomes natural that obtaining financial benefits not only gives rise to sharing accommodation but also facilitates its growth. We tested our model in the Chinese context for it deserves attention due to the massive size of the market. In addition, we highlighted the difference between these two contexts when it comes to examining host behavior. What motivates hosts to list multiple properties might be attributed to the network effect, suggesting that a host's listing behavior on the platform is influenced by those who already participated on the platform in the first place (Evans and Schmalensee, 2016). Not only is the network effect evident on the demand side that leads to an increasing number of guests as travelers, but hosts also jump on the latest trend to parade their entrepreneurial aspirations on the supply side.

(Insert Figure 1 about here)

\section{METHODOLOGY}

\subsection{Data and Measures}

We used a Python procedure to scrape publicly available information from Xiaozhu (xiaozhu.com). Python is a widely used programming language for general-purpose programming. It is a powerful tool for web scraping, often called web crawling or web spidering, to programmatically go over a collection of web pages and extract data.

Founded in August 2012, Xiaozhu is a leading accommodation-sharing platform in China. As of March 2017, it offered 80,000 properties in more than 250 Chinese domestic destinations (Xiaozhu, 2018). China is a massive market in terms of user base, travel demand, and accommodation supply, which may have explained the rapid development of the platform and its accommodation-sharing community. This booming market makes us believe that it is 
vital to investigate the growth of multi-listing on accommodation-sharing platforms.

Xiaozhu displays a unique host profile page on which we can observe the release date of each property managed by a host as well as host characteristics. By collecting information on property release dates, we were able to track the multiple listing behavior of hosts over time. We focused on hosts who published more than one property (i.e., multiple listing) upon the data collection of this study in Beijing, the most populous Chinese city with long-established accommodation-sharing services. A host was sampled as long as he or she started listing the second property in a given month under investigation. Our sample includes 3,199 observations of 252 multi-listing hosts who managed 815 properties from September 2012 to October 2016 (49 months). We focused on individual hosts' multiple listing behavior. Therefore, we excluded from our sample professional hosts such as "mega hosts," who are usually hotel companies, property managers, and a new breed of entrepreneurs to market their available properties. In addition, we dropped hosts who did not engage in multiple listing. This sample represents the total host population in Beijing who had at least two properties on the platform.

Table 1 presents the variables and summary statistics of the study. The dependent variable is the number of properties (NumExpand) operated by a host and is a function of the three types of host incentives. Specifically, financial benefit (FinBenefit) is the cumulative number of property transactions a host concluded from listing more than one property on the platform; online social interactions (SocInteract) is the number of host replies to guest reviews online; and member seniority (MemSeniority) measures the length of host membership since he or she joined the platform. We also controlled host characteristics that would influence the multiple listing behavior of hosts, including gender (Gender), age (Age), level of education (Education), types of occupation (Employment), and their management styles, including how 
they reply to guest inquires (ReplyRate), number of minutes it takes to confirm a guest reservation (ConfirmTime), and how likely they accept a guest to stay (AcceptRate), and their virtual score to signal trustworthiness (CreditScore). Table 2 presents the Pearson correlation coefficients between these variables, which are below 0.8 (Katz, 2006), indicating that our estimation is not subject to collinearity.

(Insert Table 1, Table 2, and Figure 2 about here)

Figure 2 presents the distributions of the total number of properties among the hosts. Slightly more than half (50.5\%) of the hosts were multi-listing hosts. In particular, we observed a long tail in the distribution of the hosts. A large number of properties (6-10 properties) managed by the hosts occur far from the center of the distribution, with a slight jump in the number of hosts who managed 9 properties $(1.1 \%)$ and 10 properties $(1.9 \%)$. These hosts are clearly "megahosts" with a larger number of properties on the accommodation platform.

\subsection{Model Specifications}

We model the number of properties (NumExpand) of host $i$ in month $t$ on the platform as the function of his or her financial (FinBenefit), social (SocInteract), and experience incentives (MemSeniority) as well as a wide range of host characteristics:

$$
\text { NumExpand }_{i t}=\alpha+\delta^{\prime} \text { INCENTIVE }_{i t-1}+\gamma^{\prime} H O S T_{i}+\varepsilon_{i t},
$$

where INCENTIVE $E_{i t-1}$ is a vector of covariates representing host incentives and their interactions. We focus on estimating the parameter $\delta$, which assesses the effects of host incentives and their interaction on the multiple listing behavior of hosts. Besides the primary incentive variables, we control a vector of host characteristics $\left(H_{O S T}\right.$, ), including Gender, Age, Education, Employment, CreditScore, ReplyRate, ConfirmTime and AcceptRate, which may also affect the number of properties from a host in a given month. Parameter $\gamma$ examines the effects of these controls on the 
multiple listing behavior of hosts. $\varepsilon_{i t}$ is a random error.

\section{RESULTS AND DISCUSSION}

\subsection{Analytical Procedure}

We adopted a hierarchical and stepwise estimation approach, through which host characteristics controls, the primary incentive variables, and the interactions of these incentive variables were included sequentially in multiple regression models. The hierarchical and stepwise approach enables us to observe the increased explanatory power of each model with one incentive variable included in the regression each time. For each model, we used a blend of econometric estimations with error specifications to cross-validate the robustness of the estimated effects. As Table 3 shows, we implemented the estimation with standard errors in Column (a), followed by the estimations with the robust standard errors in Column (b) and the

robust standard errors clustered at the host level in Column (c). Robust standard errors clustered at the host level were used to reduce heteroscedasticity concerns. While robust standard errors allow for heterogeneity on the error term, clustering such error terms within a host increases the confidence intervals because we allowed independence across hosts but the correlation of observations within hosts (Sarzosa, 2012).

(Insert Table 3 about here)

\subsection{Effects of Host Characteristics on Hosts' Multiple Listing Behavior}

The estimated effects in Column (a) of each model are discussed below, followed by robustness checks of the estimated effects in Columns (b) and (c). In order to control for the effects of host characteristics on the multiple listing behavior, we examined the variance in the number of properties explained by these variables. Model 1a presents the estimations of the 
effects of host controls on the number of properties. The model explained $38.4 \%$ of the variance in the number of properties, indicating that the number of properties can be attributed to host characteristics. In particular, we found that age and education were statistically significant in explaining the multiple listing behavior of hosts. Compared to those born between 1940 and 1949 (the base group), younger hosts were more likely to increase their properties. The multiple listing behavior is mostly driven by hosts who were born between 1960 and $1969\left(0.752^{*}\right), 1970$ and $1979\left(1.080^{* *}\right)$, and 1980 and $1989\left(1.619^{* * *}\right)$. Those born between 1990 and 1999 were among the youngest but also more active in multi-listing $\left(1.222^{* * *}\right)$. In other words, multiple properties were largely driven by those below 40 years old. In addition, it is intriguing that hosts with a high school education tended to list more than those with bachelor's degrees (the base group) $\left(1.784^{* * *}\right)$. We also found that hosts' behavioral characteristics, such as their reply rates and credits, affected their listing behavior. These results show that reply rates $\left(7.082^{* * *}\right)$ were positively associated with the number of their properties, so too were credit scores $\left(0.009^{* *}\right)$.

We did not find evidence for the effects of gender and employment on the number of properties. It is plausible that both male and female hosts are capable of managing accommodation-sharing services. Some studies attributed the advent of the sharing economy to the shrink of job opportunities in the 2007/08 financial crisis, suggesting that high unemployment may force people to participate in sharing economy services (Botsman and Rogers, 2011). However, because of the insignificant effect of employment on the number of properties, the relationship between the two might be a context-specific issue. Since Xiaozhu was founded almost five years after the financial crisis, listing properties on the platform may not be seen by Chinese hosts as an alternative to formal employment as it was for Airbnb in 2008.

\subsection{Effects of Financial, Social, and Experience Incentives on Hosts' Multiple Listing}




\section{Behavior}

After controlling for the effects of host characteristics in Model 2a, we found that financial, social, and experience incentives combined explained an additional $28.3 \%$ of the variance in the number of properties. Specifically, we found that financial benefits $\left(0.002^{* * *}\right)$ positively affected the current number of properties, which supports H1. This result indicates that hosts' multiple listing behavior is significantly driven by the financial benefits obtained in preceding periods. While previous studies did not explicitly draw a linkage between financial benefits and hosts' multiple listing behavior nor attempted to quantify such a positive relationship (Ikkala, 2014; Ikkala and Lampinen, 2015; Jung et al., 2016), our study lent strong support to such a linkage. Moreover, we argue that the financial benefits may not only encourage hosts to participate in accommodation-sharing services in the first place but also motivate them to increase their properties if they wish to generate enough transactions after participation. It is also worth noting that the financial benefits that drive hosts to increase their properties can be interpreted differently depending on the lifecycle of the sharing economy as well as hosts' membership seniority. The advent of sharing accommodation, exemplified by Airbnb, was primarily due to hosts' motivation in obtaining additional income or recouping values of their housing asset in the first place (Botsman and Rogers, 2011; Jefferson-Jones, 2015). Yet the growth of the sharing accommodation gradually leads to the emergence of multi-listing hosts and even professional hosts, for whom participating on the platform has less to do with earning additional income but more to do with fulfilling entrepreneurial aspirations.

Online social interaction, alongside the financial benefits, was discussed by previous studies in spurring the growth of accommodation-sharing services (Jefferson-Jones, 2016). Our result lends empirical support to the positive effect of online social interactions $\left(0.135^{*}\right)$ on 
hosts' multiple listing behavior, supporting $\mathrm{H} 2$. Hosts need to devote time to engaging with guests in order to establish meaningful interactions. Our finding implies that such effort is perceived favorably by hosts in managing their accommodation-sharing services. It indeed takes time to engage guests online through actively reviewing and communicating with them. However, our result shows that the desire to acquire social benefits through such online engagement motivates hosts to increase their properties. A plausible explanation, according to Muchnick (2015), is that proactive online social interactions suggest unique social capital generated by the platform and valued by hosts. Besides facilitating subsequent transactions on the platform, the reciprocity of social interactions helps meet the needs of social belonging and community inclusiveness for both hosts and guests. As Jung et al. (2016) concluded, human relationship, rather than the property, is vital in boosting user satisfaction. Therefore, frequently interacting with guests on the platform can satisfy hosts, thereby incentivizing them to list more.

We also found that the longer the hosts have operated on the platform, the more likely they are to increase their properties. This result was evident in the positive association between membership seniority $\left(0.027^{* * *}\right)$ and hosts' multiple listing behavior, supporting H3. The platform of accommodation sharing has only experienced a few years of growth but is booming with an exponential increase of users, properties, and transactions. This result suggests that host experience, accumulated over the length of membership, would drive hosts to increase their properties. It takes time for a host to evaluate the success of his or her previous listing before considering multiple listing. Those who serve longer as a host on the platform can accumulate more expertise and experience about the market conditions and can, therefore, better operate the accommodation-sharing business for viable growth and expansion. A longer membership suggests increased expertise, and even community belonging, which in turn drive hosts to 
increase their properties.

\subsection{Interactions of Financial, Social, and Experience Incentives on Hosts' Multiple Listing} Behavior

We further examined the interactions among the three incentives in Model 3a, which explained $73.6 \%$ of the variance in the number of properties. The effects of these three incentives estimated in Model 3a are consistent with those in Models 1a and 2a, indicating the robustness of the estimated effects. In addition, we found that the effect of financial benefits is magnified in conjunction with social incentives $\left(0.002^{*}\right)$, supporting H4a. This result shows that the financial and social incentives complement each other, jointly driving hosts' multiple listing behavior. This finding echoes Lampinen and Cheshire (2016), who illustrated that financial benefits could not only enhance hosts' intrinsic motivations to engage in sharing economy services but also facilitate subsequent social exchanges and interactions on the platform. In addition to the positive effect of financial benefits on the number of properties, we found that online social interactions would magnify such effect and jointly drive hosts' multiple listing behavior.

We found that membership seniority negatively moderates the effect of financial benefits ($0.001 * * *)$ and online social interactions $(-0.024 *)$ on hosts' multiple listing behavior, rejecting $\mathrm{H} 4 \mathrm{~b}$ and $\mathrm{H} 4 \mathrm{c}$. These findings indicate that, as host membership lengthens, hosts are less motivated to increase their properties due to the diminished financial and social returns. These results suggest that incumbent hosts with a longer membership on the platform are less willing to increase their properties given the constraints of their financial capability as well as time and effort devoted to managing multiple properties. Hosts on the platform tend to increase their properties due to the short-term financial or social incentives, but the effects of these incentives may diminish as their membership lengthens. This explains why the number of properties 
operated by a single host has a ceiling of around 10 in our study.

\section{CONCLUSION AND IMPLICATIONS}

\subsection{Conclusions}

This study explored an important but under-researched question: what incentivizes hosts to increase their properties on accommodation-sharing platforms? It examined three incentives of hosts' multiple listing behavior, including financial benefits, online social interactions, and membership seniority, as well as their interplay in driving the number of properties. The empirical findings have shown that these three incentives have significantly positive yet shortlived effects on hosts' multiple listing behavior. As hosts' membership ages, they are less likely to increase their properties on the platform due to the diminished financial and social benefits.

\subsection{Theoretical Implications}

Previous research has been largely devoted to examining the demand side of the sharing economy (Guttentag, 2015; Lee et al., 2015), particularly consumer motivation to use accommodation-sharing services (e.g., Tussyadiah and Zach, 2017). This study is one of the early attempts to understand what incentivizes hosts to increase their properties on accommodation-sharing platforms. It adds to the growing body of literature on the sharing economy by providing unique insights into the supply drivers at the host level. Specifically, it contributes to the literature by evidencing the effects of financial, social, and experience incentives on hosts' multiple listing behavior.

While previous research suggested that both financial and social incentives can explain the advent of the sharing economy as well as host behavior on accommodation sharing platforms, most of the research assumptions are either qualitative or untestable (Botsman and 
Rogers, 2011; Ikkala, 2014; Ikkala and Lampinen, 2015). This study advances this body of research by developing a three-dimensional host incentive framework and examines whether and to what extent multifaceted incentives can drive hosts' multiple listing behavior. In other words, we identified and verified the microeconomic foundation for the growth of accommodationsharing services, which is driven by financial benefits, online social interactions and membership seniority at the host level. The interplay between these incentives further demonstrates the interdependence and complexity of supply drivers of sharing accommodation at the host level.

Extant research on hosts mostly relied on behavioral intention-based surveys (Hawlitschek et al., 2016), which provided first-hand information about users' perception on accommodation sharing, yet the survey data is not effective in tracking hosts' actual listing behavior in the real world. This study thus demonstrates that analyzing hosts' multiple listing behavior can enhance our understanding of the growth of sharing accommodation at the macro level. Since in the big data era, torrents of host activity data are available on accommodation sharing platforms, hospitality research can benefit from action-driven, behavior-based business insights about how hosts increase their properties and grow the supply over time. Different from the extant research, our study draws upon the econometric approach and collects actual host activity data during their tenure with the accommodation sharing platform. Through the lens of data analytics, we are able to uncover the host-driven growth of properties and thus supplement preliminary findings in the literature.

Finally, unlike extant literature which focused on accommodation sharing (e.g., Airbnb) in the Western context (e.g., Ikkala, 2014; Ikkala and Lampinen, 2015), we focused on Xiaozhu.com, a variant of Airbnb in China, where hosts would behave differently from their counterparts in the UK or the US. While both Airbnb and Xiaozhu.com are accommodation- 
sharing services and might be indifferent on the demand side, hosts would behave differently on the two platforms after all, especially when it comes to the incentives of their multiple listing behavior and the constraints from governmental regulations.

\subsection{Practical Implications}

As accommodation-sharing services continue to evolve, this study reveals how these platforms (e.g., Airbnb and Xiaozhu) incentivize and motivate hosts to scale up supply. Our findings provide several insightful business suggestions for accommodation-sharing platforms as well as hosts who reside on these platforms. Table 4 charts several areas, where our findings can be helpful for the healthy growth of accommodation-sharing services.

(Insert Table 4 about here)

First, our study emphasizes the importance of host retention and sustainable expansion on accommodation-sharing platforms. For startups like Xiaozhu and Airbnb, acquiring as many users (both guests and hosts) as possible to trigger strong network effects is the top priority. Our study, however, makes the first attempt to underline the importance of host retention. We empirically confirmed that financial, social and experience incentives drive hosts to increase their properties on the platform. Besides actively scaling up the number of hosts, accommodation-sharing platforms should retain hosts after the acquisition and minimize their dropout rates. Despite no employment contract signed between hosts and the platform, the bond between the two can be enhanced through the platform providing membership services and reward programs for hosts. For example, platforms can help hosts promote their properties by elevating them to the top of search results, or rewarding hosts with multiple properties using a symbolic badge (e.g., Diamond Host with five properties, Silver Host with 3 properties, etc.). The ultimate goal is to establish a support community for hosts and ensure their stay on the 
platform, which is important for the viability of accommodation-sharing services.

In particular, the social incentive is the most important driver among the three incentives.

A $1 \%$ increase in online social interactions led hosts to increase the number of their properties by $13.5 \%$. This finding clearly shows that social incentive outweighs financial incentive in affecting hosts' multiple listing behavior. Therefore, we suggest that burgeoning accommodation-sharing platforms support hosts to bridge the two-way communication between hosts and guests. Monetary rewards, such as reduced commission fees and status badges, could be assigned to hosts who proactively review guests and communicate online with them. In addition, platforms can set up personal communication channels, such as online host communities, where hosts can share experience and learn from each other to interact better with their guests. Such host support practices can motivate hosts to engage more in online social interaction and communication with guests, thereby improving host service through proactively responding to customer feedback.

Furthermore, our findings suggest that social incentives complement financial incentives in affecting hosts' multiple listing behavior, yet such positive effects wane as hosts become more experienced on the platform. As a consequence, hosts become less responsive to financial and social incentives. Platforms should consider such timing when deciding to incentivize hosts. For example, platforms, on the one hand, should target novice hosts who have little experience and, on the other hand, understand the lifecycle of hosts and offer incentive opportunities through appropriate timing accordingly.

\subsection{Limitations and Future Research}

This study is not without limitations. First, although the field evidence from the accommodation-sharing platform allows us to examine multi-dimensional incentives that drive hosts' multiple listing behavior, other online unobservable factors, such as hosts' income and 
other household demographics, would also be at play. Future studies can gather such information through host surveys, and thus extend the scope of our study. Second, hosts on platforms such as Airbnb reportedly register multiple fake accounts, one per listing (SubletSpy, 2016), but many of the accounts are owned by the same host. If this is also the case for Xiaozhu, we may be subject to measurement errors. Yet, it is impossible to verify host accounts or discern whether one host owns multiple accounts unless Xiaozhu initiates a platform-wide scrutiny on the ownership of existing host accounts. Third, due to the lack of data, we could not observe the employment status of the multi-listing hosts, which would potentially affect the performance and quality of their properties. For example, if a multi-listing host is running multiple properties on a full-time basis without formal employment, he or she would likely operate the multi-listing portfolio differently from his or her counterparts who only operate one property. We thus expect different performances and qualities between these full-time hosts and hosts who operate properties in their spare time. Although we could not control the employment status of multi-listing hosts, we hope future scholars could conduct offline surveys or interviews to identify the employment attributes of hosts. Finally, although this study provides compelling cross-cultural implications for accommodation-sharing services in an emerging market (Beijing, China), its findings may not be generalized to other markets. Future studies can consider replicating our analytical framework and analysis using data from different markets, which may come up with insightful comparisons. 


\section{REFERENCES}

Airbnb (2018), “About us.” Retrieved from https://press.airbnb.com/en-uk/about-us/

Botsman, R. and Rogers, R. (2011), What's mine is yours: How collaborative consumption is changing the way we live, HarperCollins, UK.

Breese, J. (2018), "Benefits of Being an Airbnb Host", Learn Airbnb, accessed on https://learnairbnb.com/benefits-airbnb-host/

Evans, D. S. and Schmalensee, R. (2016), Matchmakers: The new economics of multisided platforms, Harvard Business Review Press, Massachusetts: Boston.

Fradkin, A., Grewal, E., Holtz, D. and Pearson, M. (2016), “Bias and reciprocity in online reviews: Evidence from field experiments on Airbnb", in Proceedings of the sixteenth ACM conference on economics and computation, New York, NY, USA: ACM, pp. 641641.

Gomes, R. (2014), "Optimal auction design in two-sided markets", RAND Journal of Economics, Vol. 45 No. 2, pp. 248-272.

Guttentag, D. (2015), “Airbnb: Disruptive innovation and the rise of an informal tourism accommodation sector", Current Issues in Tourism, Vol. 18 No. 12, pp. 1192-1217.

Hawlitschek, F., Teubner, T. and Gimpel, H. (2016), "Understanding the sharing economyDrivers and impediments for participation in peer-to-peer rental", in 2016 49th Hawaii international conference on system sciences (HICSS), pp. 4782-4791.

Heo, C. Y. (2016), "Sharing economy and prospects in tourism research", Annals of Tourism Research, Vol. 58 No. C, pp. 166-170.

Ikkala, T. (2014), "Monetary network hospitality and sociability: A study of hospitality exchange in the context of Airbnb", Unpublished thesis, retrieved from 
https://helda.helsinki.fi/handle/10138/135408

Ikkala, T. and Lampinen, A. (2015), "Monetizing network hospitality: Hospitality and sociability in the context of Airbnb", in Proceedings of the 18th ACM conference on computer supported cooperative work \& social computing, New York, NY, USA: ACM, pp. 10331044.

Jefferson-Jones, J. (2015), “Can short-term rental arrangements increase home values? A case for Airbnb and other home sharing arrangements", SSRN Scholarly Paper No. ID 2714051. Rochester, NY: Social Science Research Network. Retrieved from http://papers.ssrn.com/abstract=2714051

Jefferson-Jones, J. (2016), “Shut out of Airbnb: A proposal for remedying housing discrimination in the modern sharing economy", SSRN Scholarly Paper No. ID 2772078. Rochester, NY: Social Science Research Network. Retrieved from http://papers.ssrn.com/abstract=2772078

Jung, J., Yoon, S., Kim, S., Park, S., Lee, K.-P. and Lee, U. (2016), “Social or financial goals? Comparative analysis of user behaviors in Couchsurfing and Airbnb", in Proceedings of the 2016 CHI conference extended abstracts on human factors in computing systems, New York, NY, USA: ACM, pp. 2857-2863.

Kakar, V., Franco, J., Voelz, J. and Wu, J. (2016), “Effects of host race information on Airbnb listing prices in San Francisco", MPRA Paper, retrieved from https://mpra.ub.unimuenchen.de/69974/

Katz, M. (2006), Multivariable analysis: A practical guide for clinicians, Cambridge University Press, UK.

Kwok, L. and Xie, K. (2018), "Pricing strategies on Airbnb: Are multi-unit host revenue pros?" 
International Journal of Hospitality Management, forthcoming https://doi.org/10.1016/j.ijhm.2018.09.013

Lampinen, A. and Cheshire, C. (2016), "Hosting via Airbnb: Motivations and financial assurances in monetized network hospitality", in Proceedings of the $2016 \mathrm{CHI}$ conference on human factors in computing systems, ACM, pp. 1669-1680.

Lee, Y. and Song, S. (2010), “An empirical investigation of electronic word-of-mouth: Informational motive and corporate response strategy", Computers in Human Behavior, Vol. 26 No. 5, pp. 1073-1080.

Lee, D., Hyun, W., Ryu, J., Lee, W. J., Rhee, W. and Suh, B. (2015), “An analysis of social features associated with room sales of Airbnb", in Proceedings of the 18th ACM conference companion on computer supported cooperative work \& social computing, New York, NY, USA: ACM, pp. 219-222.

Li, J., Moreno, A. and Zhang, D. J. (2015), “Agent behavior in the sharing economy: Evidence from Airbnb", SSRN Scholarly Paper No. ID 2708279. Rochester, NY: Social Science Research Network. Retrieved from http://papers.ssrn.com/abstract=2708279

Litvak, J. (2016), “Could helpful short-term rental platforms be negatively affecting the housing market?" IMSAloquium Student Investigation Showcase. Retrieved from http://digitalcommons.imsa.edu/sir_presentations/2016/oralsession1/36

Martin, C. J., Upham, P. and Budd, L. (2015), “Commercial orientation in grassroots social innovation: Insights from the sharing economy", Ecological Economics, Vol. 118, pp. 240-251.

McClelland, D. C. (1961), The achieving society, Free Press, New York, NY.

Muchnick, S. (2015), “Tips for using Airbnb: How to screen potential guests”, Guesty. Retrieved 
from: https://www.guesty.com/blog/tips-for-using-airbnb-to-screen-guests/

Parker, G. G., Alstyne, M. W. V. and Choudary, S. P. (2016), Platform revolution: How networked markets are transforming the economy and how to make them work for you, W. W. Norton \& Company, New York, NY.

Parker, G. G. and Van Alstyne, M. W. (2005), “Two-sided network effects: A theory of information product design", Management Science, Vol. 51 No. 10, pp. 1494-1504.

Rochet, J. C. and Tirole, J. (2008), "Tying in two-sided markets and the honor all cards rule", International Journal of Industrial Organization, Vol. 26 No. 6, pp. 1333-1347.

Sarzosa, S. (2012), "Introduction to robust and clustered standard errors", Empirical Microeconomics. Retrieved November 30, 2016, from http://econweb.umd.edu/ sarzosa/teach/2/Disc2_Cluster_handout.pdf

Slee, T. (2016), What's yours is mine: Against the sharing economy, Between the Lines, Toronto, Canada.

SubletSpy (2016), “Airbnb is lying again: This time about 'One Host, One Home'”, retrieved May 2, 2017 from https://medium.com/@subletspy/airbnb-is-lying-again-this-timeabout-one-host-one-home-7ead84febcc

Tussyadiah, I. P. and Zach, F. (2017), “Identifying salient attributes of peer-to-peer accommodation experience", Journal of Travel \& Tourism Marketing, Vol. 34 No. 5, pp. 636-652.

Vaughan, R. and Daverio, R. (2016), "Assessing the size and presence of the collaborative economy in Europe", PricewaterhouseCoopers. Retrieved from http://www.pwc.co.uk/issues/megatrends/collisions/sharingeconomy/outlook-for-thesharing-economy-in-the-uk-2016.html 
Wu, E. A. A. (2016), "Learning in peer-to-peer markets: evidence from Airbnb”, retrieved from http://bibliotecadigital.fgv.br/dspace/handle/10438/16568

Xiaozhu (2018), “About us.” Retrieved from http://www.xiaozhu.com/aboutus

Xie, K., Zhang, Z. L. and Zhang, Z. Q. (2014), “The business value of online consumer reviews and management response to hotel performance", International Journal of Hospitality Management, Vol. 43 No. 1, pp. 1-12.

Xie, K. and Mao, Z. (2017), “The impacts of quality and quantity attributes of Airbnb hosts on listing performance”, International Journal of Contemporary Hospitality Management, Vol. 29 No. 9, pp. 2240-2260.

Xie, K. and So, K. (2018), "The effects of expert reviews on future reputation, popularity, and financial performance of hotels: Insights from data analytics", Journal of Hospitality \& Tourism Research, Vol. 42 No. 8, pp. 1187-1209.

Zervas, G., Proserpio, D. and Byers, J. (2015), “A first look at online reputation on Airbnb: Where every stay is above average", retrieved from http://papers.ssrn.com/abstract $=2554500$ 


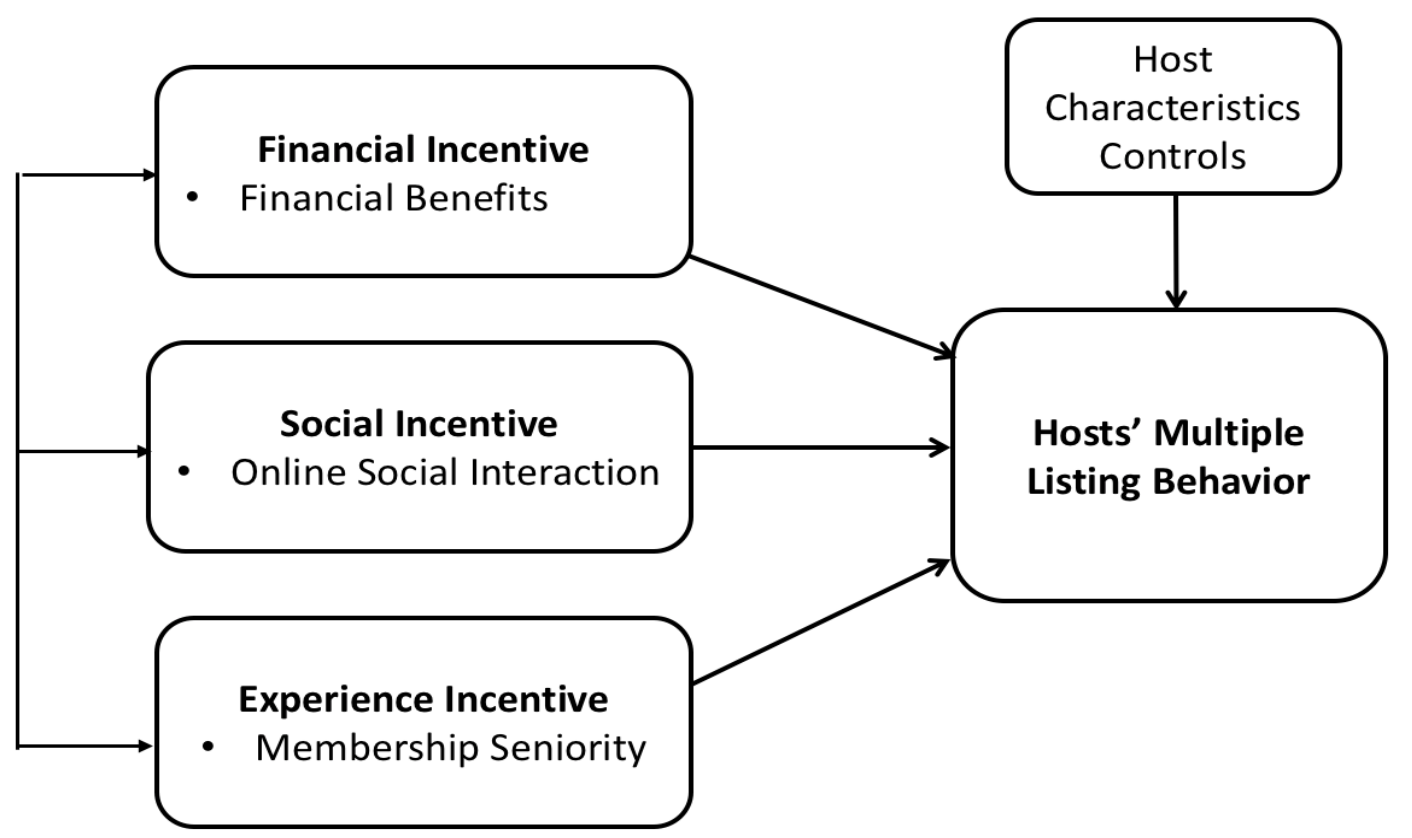

Figure 1. Research Framework 
Table 1. Variable Definitions and Summary Statistics

\begin{tabular}{|c|c|c|c|c|c|c|}
\hline Category & Variable & Definition & Mean & Std. Dev. & Min & Max \\
\hline $\begin{array}{l}\text { Dependent } \\
\text { Variable }\end{array}$ & NumExpand & Number of properties a host operated in a given month & 2.27 & 1.90 & 1 & 10 \\
\hline \multirow[t]{3}{*}{ Host Incentives } & FinBenefit & Number of successful transactions achieved by a host in a given month & 84.34 & 171.75 & 0 & 1,954 \\
\hline & SocInteract & $\begin{array}{l}\text { Number of reviews about the guests posted by a host divided by the number of } \\
\text { reviews about the hosts posted by a guest in a given month }\end{array}$ & 0.96 & 0.41 & 0 & 6.33 \\
\hline & MemSeniority & $\begin{array}{l}\text { Number of months elapsed since a host registered with xiaozhu.com in a given } \\
\text { month }\end{array}$ & 10.13 & 8.09 & 0 & 49 \\
\hline \multirow[t]{8}{*}{ Host Controls } & Gender & Dummy variable of host gender, with values of $1=$ male and $0=$ female & 0.45 & 0.50 & 0 & 1 \\
\hline & Age & $\begin{array}{l}\text { Categorical variable of the age (in decades) of hosts measured, with values of } 40 \mathrm{~s} \\
=\text { born in } 1940-1949 \text { (the base category), } 50 \mathrm{~s}=\text { born in } 1950-1959,60 \mathrm{~s}=\text { born in } \\
1960-1969,70 \mathrm{~s}=\text { born in } 1970-1979,80 \mathrm{~s}=\text { born in } 1980-1989 \text {, and } 90 \mathrm{~s}=\text { born in } \\
1990-1999\end{array}$ & 76.08 & 9.23 & 40 & 90 \\
\hline & Education & $\begin{array}{l}\text { Categorical variable of the highest level of host education, with values of } 1= \\
\text { junior high school, } 2=\text { high school, } 3=\text { secondary vocational school, } 4=\text { specialist } \\
\text { college, } 5=\text { university bachelor's degree (the base category), } 6=\text { master's degree, } \\
\text { and } 7=\text { doctorate }\end{array}$ & 5.76 & 1.12 & 1 & 7 \\
\hline & Employment & $\begin{array}{l}\text { Categorical variable of the host occupation, with values of } 1=\text { employed in } \\
\text { technology industries, } 2=\text { employed in hospitality industries, } 3=\text { employed in } \\
\text { industries other than technology and hospitality, } 4=\text { self-employed in } \\
\text { accommodation-sharing services, and } 5=\text { self-employed in industries other than } \\
\text { accommodation-sharing services (the base category) }\end{array}$ & 1.07 & 1.45 & 1 & 5 \\
\hline & CreditScore & $\begin{array}{l}\text { Number of credit scores issued by a third-party company to evaluate host } \\
\text { credibility online[1], with the score ranging from } 350 \text { to } 950\end{array}$ & 727.00 & 45.50 & 579 & 812 \\
\hline & ReplyRate & Number of host replies divided by the number of online inquiries in a given month & 0.95 & 0.09 & 0 & 1 \\
\hline & Confirm Time & $\begin{array}{l}\text { Number of minutes it takes a host to whether or not to confirm a reservation } \\
\text { request in a given month }\end{array}$ & 5.17 & 4.35 & 0 & 71 \\
\hline & AcceptRate & $\begin{array}{l}\text { Number of accepted reservations divided by the number of reservation requests in } \\
\text { a given month }\end{array}$ & 0.86 & 0.13 & 0 & 1 \\
\hline
\end{tabular}

Notes: [1] Source: https://zmxy.antgroup.com/index.htm 
Table 2. Correlation Matrix

\begin{tabular}{|c|c|c|c|c|c|c|c|c|c|c|c|c|}
\hline & & $(1)$ & (2) & (3) & (4) & (5) & (6) & (7) & (8) & (9) & (10) & (11) \\
\hline (1) & FinBenefit & 1.00 & & & & & & & & & & \\
\hline (2) & SocInteract & 0.02 & 1.00 & & & & & & & & & \\
\hline (3) & MemSeniority & 0.39 & -0.03 & 1.00 & & & & & & & & \\
\hline (4) & Gender & -0.05 & -0.01 & 0.02 & 1.00 & & & & & & & \\
\hline (5) & Age & 0.10 & -0.02 & -0.06 & 0.02 & 1.00 & & & & & & \\
\hline (6) & Education & -0.06 & 0.14 & -0.03 & 0.06 & -0.22 & 1.00 & & & & & \\
\hline (7) & Employment & 0.00 & 0.10 & -0.02 & -0.05 & 0.04 & 0.07 & 1.00 & & & & \\
\hline (8) & CreditScore & 0.05 & -0.02 & 0.07 & -0.06 & 0.12 & -0.03 & -0.11 & 1.00 & & & \\
\hline (9) & ReplyRate & 0.10 & 0.18 & -0.06 & -0.07 & 0.06 & 0.02 & -0.04 & 0.15 & 1.00 & & \\
\hline (10) & ConfirmTime & -0.07 & -0.18 & -0.02 & 0.03 & -0.03 & 0.02 & 0.07 & -0.08 & -0.42 & 1.00 & \\
\hline (11) & AcceptRate & 0.13 & 0.18 & -0.02 & -0.03 & -0.08 & -0.02 & -0.17 & 0.02 & 0.60 & -0.45 & 1.00 \\
\hline
\end{tabular}




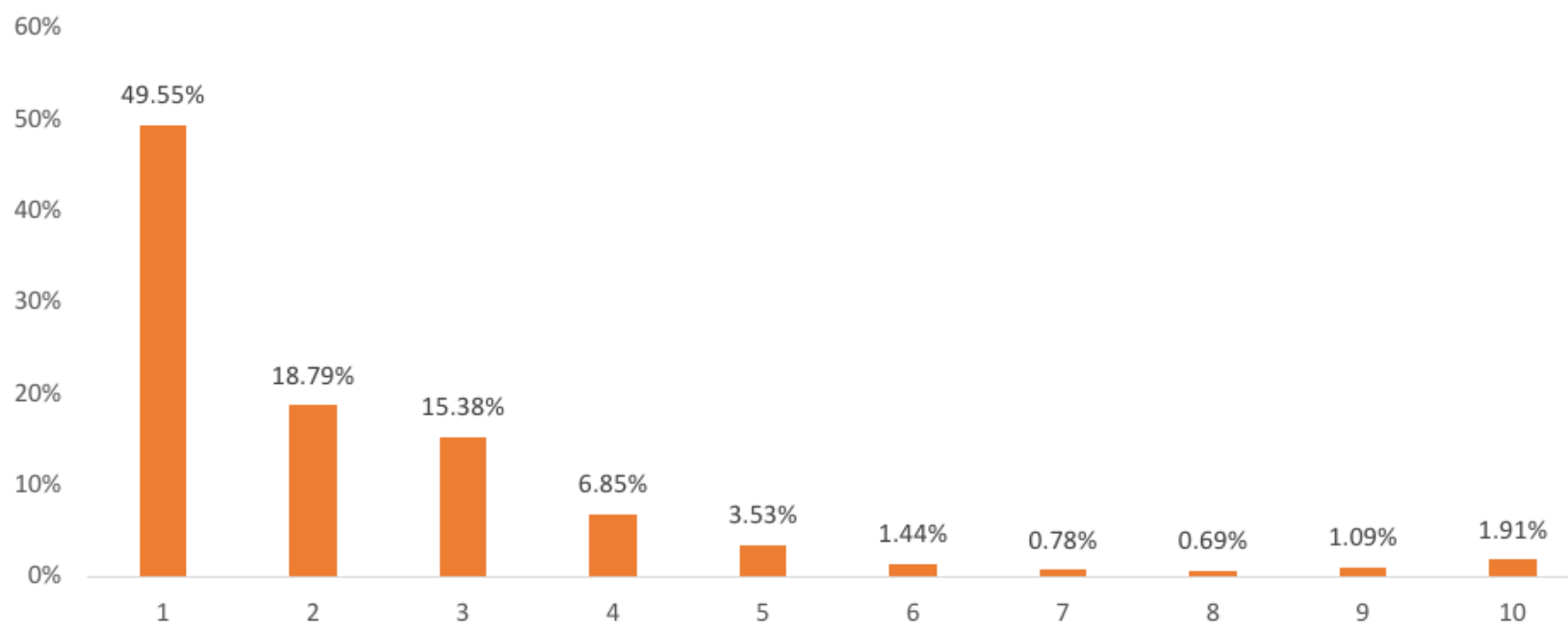

Figure 2. Distribution of the Total Number of Properties Managed by Hosts 
Table 3. Estimated Effects of Host Incentives on Multiple Listing Behavior

\begin{tabular}{|c|c|c|c|c|c|c|c|c|c|}
\hline & \multicolumn{9}{|c|}{ NumExpand } \\
\hline & \multicolumn{3}{|c|}{ Model 1} & \multicolumn{3}{|c|}{ Model 2} & \multicolumn{3}{|c|}{ Model 3} \\
\hline & (1a) & (1b) & $(1 \mathrm{c})$ & $(2 a)$ & $(2 b)$ & $(2 c)$ & $(3 a)$ & $(3 b)$ & $(3 c)$ \\
\hline \multicolumn{10}{|l|}{ Primary Variables } \\
\hline EcoIncent & & & & $\begin{array}{l}0.002 * * * \\
(0.000)\end{array}$ & $\begin{array}{l}0.002 * * * \\
(0.000)\end{array}$ & $\begin{array}{l}0.002 * * * \\
(0.001)\end{array}$ & $\begin{array}{l}0.008 * * * \\
(0.000)\end{array}$ & $\begin{array}{l}0.008 * * * \\
(0.000)\end{array}$ & $\begin{array}{l}0.008 * * \\
(0.015)\end{array}$ \\
\hline SocIncent & & & & $\begin{array}{l}0.135^{*} \\
(0.051)\end{array}$ & $\begin{array}{l}0.135^{* *} \\
(0.031)\end{array}$ & $\begin{array}{l}0.135^{* *} \\
(0.028)\end{array}$ & $\begin{array}{l}0.181^{*} \\
(0.057)\end{array}$ & $\begin{array}{l}0.181^{*} \\
(0.087)\end{array}$ & $\begin{array}{l}0.181 * * \\
(0.030)\end{array}$ \\
\hline ComIncent & & & & $\begin{array}{l}0.027^{* * *} \\
(0.000)\end{array}$ & $\begin{array}{l}0.027^{* * *} \\
(0.000)\end{array}$ & $\begin{array}{l}0.027^{*} \\
(0.079)\end{array}$ & $\begin{array}{l}0.041 * * * \\
(0.001)\end{array}$ & $\begin{array}{l}0.041 * * \\
(0.034)\end{array}$ & $\begin{array}{l}0.041 * * \\
(0.027)\end{array}$ \\
\hline EcoIncent $\times$ SocIncent & & & & & & & $\begin{array}{l}0.002 * \\
(0.088)\end{array}$ & $\begin{array}{l}0.002 * * \\
(0.014)\end{array}$ & $\begin{array}{l}0.002 * \\
(0.051)\end{array}$ \\
\hline EcoIncent $\times$ ComIncent & & & & & & & $\begin{array}{l}-0.001 * * * \\
(0.000)\end{array}$ & $\begin{array}{l}-0.001 * * * \\
(0.000)\end{array}$ & $\begin{array}{l}-0.001 * * * \\
(0.007)\end{array}$ \\
\hline SocIncent $\times$ ComIncent & & & & & & & $\begin{array}{l}-0.024^{*} \\
(0.052)\end{array}$ & $\begin{array}{l}-0.024 * * \\
(0.021)\end{array}$ & $\begin{array}{l}-0.024 * * \\
(0.047)\end{array}$ \\
\hline \multicolumn{10}{|l|}{ Host Controls } \\
\hline Gender & $\begin{array}{c}0.055 \\
(0.780)\end{array}$ & $\begin{array}{c}0.055 \\
(0.714)\end{array}$ & $\begin{array}{c}0.055 \\
(0.180)\end{array}$ & $\begin{array}{l}0.285 * \\
(0.092)\end{array}$ & $\begin{array}{c}0.285 * * \\
(0.022)\end{array}$ & $\begin{array}{c}0.285^{* * *} * \\
(0.000)\end{array}$ & $\begin{array}{c}0.108 \\
(0.532)\end{array}$ & $\begin{array}{c}0.108 \\
(0.494)\end{array}$ & $\begin{array}{c}0.108 \\
(0.520)\end{array}$ \\
\hline \multicolumn{10}{|l|}{ Age } \\
\hline Born 1950-1959 & $\begin{array}{c}0.001 \\
(0.453)\end{array}$ & $\begin{array}{c}0.001 \\
(0.400)\end{array}$ & $\begin{array}{c}0.001 \\
(0.479)\end{array}$ & $\begin{array}{c}0.001 \\
(0.312)\end{array}$ & $\begin{array}{c}0.001 \\
(0.334)\end{array}$ & $\begin{array}{c}0.001 \\
(0.330)\end{array}$ & $\begin{array}{c}0.001 \\
(0.733)\end{array}$ & $\begin{array}{c}0.001 \\
(0.740)\end{array}$ & $\begin{array}{c}0.001 \\
(0.797)\end{array}$ \\
\hline Born 1960-1969 & $\begin{array}{l}0.752 * \\
(0.088)\end{array}$ & $\begin{array}{c}0.752 * * * \\
(0.000)\end{array}$ & $\begin{array}{c}0.752 \\
(0.140)\end{array}$ & $\begin{array}{c}0.259 \\
(0.467)\end{array}$ & $\begin{array}{c}0.259 * * \\
(0.049)\end{array}$ & $\begin{array}{c}0.259 \\
(0.459)\end{array}$ & $\begin{array}{c}0.079 \\
(0.816)\end{array}$ & $\begin{array}{c}0.079 \\
(0.563)\end{array}$ & $\begin{array}{c}0.079 \\
(0.797)\end{array}$ \\
\hline Born 1970-1979 & $\begin{array}{c}1.080 * * \\
(0.014)\end{array}$ & $\begin{array}{c}1.080 * * * \\
(0.000)\end{array}$ & $\begin{array}{l}1.080 * * \\
(0.039)\end{array}$ & $\begin{array}{c}0.496 \\
(0.160)\end{array}$ & $\begin{array}{c}0.496^{* * *} \\
(0.000)\end{array}$ & $\begin{array}{c}0.496 \\
(0.115)\end{array}$ & $\begin{array}{c}0.240 \\
(0.476)\end{array}$ & $\begin{array}{l}0.240^{*} \\
(0.085)\end{array}$ & $\begin{array}{c}0.240 \\
(0.370)\end{array}$ \\
\hline Born 1980-1989 & $\begin{array}{c}1.619 * * * \\
(0.000)\end{array}$ & $\begin{array}{c}1.619 * * * \\
(0.000)\end{array}$ & $\begin{array}{c}1.619 * * * \\
(0.000)\end{array}$ & $\begin{array}{c}0.725 * * \\
(0.036)\end{array}$ & $\begin{array}{c}0.725 * * * \\
(0.000)\end{array}$ & $\begin{array}{c}0.725^{* * *} \\
(0.009)\end{array}$ & $\begin{array}{c}0.487 \\
(0.139)\end{array}$ & $\begin{array}{c}0.487 * * * \\
(0.000)\end{array}$ & $\begin{array}{c}0.487^{*} \\
(0.050)\end{array}$ \\
\hline Born 1990-1999 & $\begin{array}{c}1.222 * * * \\
(0.006)\end{array}$ & $\begin{array}{c}1.222 * * * \\
(0.000)\end{array}$ & $\begin{array}{c}1.222 * * \\
(0.013)\end{array}$ & $\begin{array}{c}0.584 \\
(0.103)\end{array}$ & $\begin{array}{c}0.584 * * * \\
(0.000)\end{array}$ & $\begin{array}{c}0.584 \\
(0.129)\end{array}$ & $\begin{array}{c}0.220 \\
(0.521)\end{array}$ & $\begin{array}{c}0.220 \\
(0.186)\end{array}$ & $\begin{array}{c}0.220 \\
(0.568)\end{array}$ \\
\hline \multicolumn{10}{|l|}{ Education } \\
\hline Junior high school & $\begin{array}{l}-0.251 \\
(0.433)\end{array}$ & $\begin{array}{c}-0.251 \\
(0.246)\end{array}$ & $\begin{array}{c}-0.251 \\
(0.577)\end{array}$ & $\begin{array}{l}-0.172 \\
(0.504)\end{array}$ & $\begin{array}{c}-0.172 \\
(0.406)\end{array}$ & $\begin{array}{c}-0.172 \\
(0.688)\end{array}$ & $\begin{array}{c}-0.152 \\
(0.535)\end{array}$ & $\begin{array}{c}-0.152 \\
(0.459)\end{array}$ & $\begin{array}{l}-0.152 \\
(0.733)\end{array}$ \\
\hline High school & $\begin{array}{c}1.784 * * * \\
(0.000)\end{array}$ & $\begin{array}{c}1.784 * * * \\
(0.000)\end{array}$ & $\begin{array}{l}1.784 * * \\
(0.021)\end{array}$ & $\begin{array}{c}1.823 * * * \\
(0.000)\end{array}$ & $\begin{array}{c}1.823 * * * \\
(0.000)\end{array}$ & $\begin{array}{c}1.823 * * * \\
(0.005)\end{array}$ & $\begin{array}{c}1.809 * * * \\
(0.000)\end{array}$ & $\begin{array}{c}1.809 * * * \\
(0.000)\end{array}$ & $\begin{array}{c}1.809 * * * \\
(0.000)\end{array}$ \\
\hline Secondary vocational school & $\begin{array}{l}-0.360 \\
(0.245)\end{array}$ & $\begin{array}{l}-0.360 \\
(0.156)\end{array}$ & $\begin{array}{l}-0.360 \\
(0.543)\end{array}$ & $\begin{array}{l}-0.144 \\
(0.565)\end{array}$ & $\begin{array}{l}-0.144 \\
(0.441)\end{array}$ & $\begin{array}{l}-0.144 \\
(0.728)\end{array}$ & $\begin{array}{l}-0.174 \\
(0.465)\end{array}$ & $\begin{array}{l}-0.174 \\
(0.312)\end{array}$ & $\begin{array}{l}-0.174 \\
(0.644)\end{array}$ \\
\hline Specialist college & 0.165 & 0.165 & 0.165 & $-0.167^{*}$ & $-0.167 *$ & -0.167 & $-0.295 * * *$ & $-0.295 * * *$ & -0.295 \\
\hline
\end{tabular}




\begin{tabular}{|c|c|c|c|c|c|c|c|c|c|}
\hline & $(0.184)$ & $(0.156)$ & $(0.692)$ & $(0.100)$ & $(0.070)$ & $(0.496)$ & $(0.003)$ & $(0.001)$ & $(0.205)$ \\
\hline \multirow[t]{2}{*}{ Master's degree } & 0.245 & $0.245^{*}$ & 0.245 & $0.274 * *$ & $0.274 * * *$ & 0.274 & 0.184 & $0.184 * *$ & 0.184 \\
\hline & $(0.101)$ & $(0.085)$ & $(0.601)$ & $(0.024)$ & $(0.007)$ & $(0.341)$ & $(0.111)$ & $(0.050)$ & $(0.432)$ \\
\hline \multirow[t]{2}{*}{ Doctorate } & -0.844 & $-0.844 * * *$ & $-0.844 * *$ & -0.435 & $-0.435^{* * *}$ & $-0.435^{*}$ & -0.255 & $-0.255^{* *}$ & -0.255 \\
\hline & $(0.137)$ & $(0.000)$ & $(0.023)$ & $(0.344)$ & $(0.001)$ & $(0.072)$ & $(0.560)$ & $(0.045)$ & $(0.253)$ \\
\hline \multicolumn{10}{|l|}{ Employment } \\
\hline \multirow[t]{2}{*}{ Employed in technology industries } & 0.146 & 0.146 & 0.146 & 0.631 & $0.631 * *$ & $0.631 * * *$ & 0.411 & 0.411 & $0.411 *$ \\
\hline & $(0.779)$ & $(0.577)$ & $(0.461)$ & $(0.157)$ & $(0.013)$ & $(0.002)$ & $(0.335)$ & $(0.102)$ & $(0.091)$ \\
\hline \multirow[t]{2}{*}{ Employed in hospitality industries } & 0.446 & 0.446 & $0.446^{* *}$ & 0.630 & 0.630 & $0.630 * * *$ & $1.000 * *$ & 1.000 & $1.000 * * *$ \\
\hline & $(0.433)$ & $(0.719)$ & $(0.033)$ & $(0.194)$ & $(0.591)$ & $(0.003)$ & $(0.032)$ & $(0.380)$ & $(0.001)$ \\
\hline \multicolumn{10}{|l|}{ Employed in industries other than } \\
\hline \multirow[t]{2}{*}{ technology and hospitality } & -0.683 & -0.683 & $-0.683 * * *$ & -0.365 & -0.365 & $-0.365 * *$ & -0.022 & -0.022 & -0.022 \\
\hline & $(0.224)$ & $(0.169)$ & $(0.000)$ & $(0.446)$ & $(0.412)$ & $(0.022)$ & $(0.961)$ & $(0.959)$ & $(0.920)$ \\
\hline \multicolumn{10}{|c|}{ Self-employed in accommodation-sharing } \\
\hline \multirow[t]{2}{*}{ services } & 0.709 & $0.709 * *$ & $0.709 * * *$ & $1.053 * * *$ & $1.053 * * *$ & $1.053 * * *$ & 0.604 & $0.604 * *$ & $0.604 * * *$ \\
\hline & $(0.133)$ & $(0.037)$ & $(0.000)$ & $(0.009)$ & $(0.000)$ & $(0.000)$ & $(0.118)$ & $(0.016)$ & $(0.003)$ \\
\hline \multirow[t]{2}{*}{ CreditScore } & $0.009 * *$ & $0.009 * *$ & $0.009 * * *$ & $0.012 * * *$ & $0.012 * * *$ & $0.012 * * *$ & $-0.010 * * *$ & $-0.010 * * *$ & $-0.010 * * *$ \\
\hline & $(0.044)$ & $(0.023)$ & $(0.000)$ & $(0.002)$ & $(0.001)$ & $(0.000)$ & $(0.003)$ & $(0.002)$ & $(0.000)$ \\
\hline \multirow[t]{2}{*}{ ReplyRate } & $7.082 * * *$ & $7.082 * * *$ & $7.082 * * *$ & $6.632 * * *$ & $6.632 * * *$ & $6.632 * * *$ & $5.693 * * *$ & $5.693 * * *$ & $5.693 * * *$ \\
\hline & $(0.001)$ & $(0.000)$ & $(0.000)$ & $(0.000)$ & $(0.000)$ & $(0.000)$ & $(0.001)$ & $(0.000)$ & $(0.000)$ \\
\hline \multirow[t]{2}{*}{ Confirm Time } & -0.085 & $-0.085 * * *$ & $-0.085 * * *$ & $-0.107^{*}$ & $-0.107 * * *$ & $-0.107 * * *$ & -0.061 & $-0.061 * * *$ & $-0.061 * *$ \\
\hline & $(0.204)$ & $(0.000)$ & $(0.000)$ & $(0.061)$ & $(0.000)$ & $(0.000)$ & $(0.263)$ & $(0.001)$ & $(0.022)$ \\
\hline \multirow[t]{2}{*}{ AcceptRate } & 1.920 & $1.920 * * *$ & $1.920 * * *$ & 1.559 & $1.559 * * *$ & $1.559 * * *$ & 0.025 & 0.025 & 0.025 \\
\hline & $(0.293)$ & $(0.002)$ & $(0.000)$ & $(0.316)$ & $(0.003)$ & $(0.000)$ & $(0.986)$ & $(0.965)$ & $(0.974)$ \\
\hline \multirow[t]{2}{*}{ Constant } & -3.780 & -3.780 & $-3.780 * *$ & -1.220 & -1.220 & -1.220 & 1.357 & 1.357 & 1.357 \\
\hline & $(0.386)$ & $(0.289)$ & $(0.046)$ & $(0.742)$ & $(0.706)$ & $(0.466)$ & $(0.702)$ & $(0.673)$ & $(0.541)$ \\
\hline Observations & 3,199 & 3,199 & 3,199 & 3,199 & 3,199 & 3,199 & 3,199 & 3,199 & 3,199 \\
\hline R-squared & 0.384 & 0.384 & 0.384 & 0.667 & 0.667 & 0.667 & 0.736 & 0.736 & 0.736 \\
\hline Mean VIF & 4.47 & 4.47 & 4.47 & 5.04 & 5.04 & 5.04 & 6.43 & 6.43 & 6.43 \\
\hline
\end{tabular}


Table 4. Summary of Practical Implications

1 Host Retention for Rewarding Programs

2 Host Support for Better Online Interactions with Guests

3 Host Engagement in Appropriate Timing

\section{Business Recommendations}

Retain hosts after the acquisition and minimize their dropout rates by offering membership services and host rewarding programs

- Promote multi-listing hosts on top of the research results

- Reward multi-listing hosts using symbolic badge (e.g., Diamond Host with 5 properties, Silver Host with 3 properties)

Provide support to hosts for bridging the two-way communication between hosts and guests

- Monetary rewards such as reduced commission fees and status badges

- Personal communication channels such as online host community where hosts can share experience and learn from each other to interact better with their guests.

Consider timing when incentivizing hosts

- Create an incentive program for hosts

- Target new hosts who have little experience on the accommodation-sharing platform 